\title{
Study on China's Sustainable Development of Rural Micro-credit
}

\author{
Lixin Tang \\ School of Management, Yangtzeu University \\ Jingzhou 434023, China \\ E-mail: tanglixin@yeah.net
}

\begin{abstract}
Rural micro-credit, which has been passed for 15 years in our China, gained great social and economic benefits, while its sustainability is still facing the challenges. This passage reviews the development course of rural micro-credit, points out the problems that existed and puts forward the corresponding suggests.
\end{abstract}

Keywords: Micro-credit rural area construction

\section{Introduction}

Micro-credit is a way of poverty alleviation. Micro-credit, as the name implies, is small amount of inputs, with the nature of the funds as a loan and the implementation of credit. Micro-credit is a financial service that targets to the poor, which core elements doesn't aim at small, but that the credit is an unsecured loan in order to ensure effective use of funds and return. At the micro-credit operation, it takes direct-to-home, the group UNPROFOR, the whole loan-to-zero also, a series of measures such as strict management. Micro-credit first introduced in Bangladesh in 1976, which also called "Meng-mode", has got the national organizations' authorization these years. The 2006 Nobel Peace Prize winner Muhammad Yunus and the Grameen Bank's biggest contribution was to open the financial means to assist the poor, while some can be self-financing their own sustainable development, and continuing to serve the more poor better. We introduced this mode into China in 1992, and made experiments at a dozen provinces and municipalities, including Yunnan Shanxi and so on, which got remarkable social and economic benefits. Micro-credit is positively advocated and implemented in our China.

\section{The development procedure of Micro-credit in China}

Micro-credit has been passed for 15 years in China from the time that Rural Development Institute Chinese Academy of Social Sciences, Duxiaoshan, has applied soft loans from GB Trust Fund in 1993.The procedure can be divided into 4 periods:

The first period (1993 1996), the source of the fond mainly depend on the international donation and soft loans without government fond basically, the key is GB-style micro-credit project.

The second period (1996 2000), at this stage, Government agencies and Financial institutions carried out Policy-oriented poverty alleviation projects of micro-credit for Operation of institutions with the help of International aid funds at the same time.

The third period (2000 2005), Rural formal financial institutions was Full-scale intervening and various projects entered into the stage of the institutionalization of the building. From 2000, at the People's Bank under the impetus of, rural credit cooperatives, as the formal financial institutions, was beginning to promote micro-credit comprehensively. Obvious characteristic at this stage is that under the support of central bank refinancing, rural credit cooperatives carried out small farmer credit on the basis of in strengthening the letter of the user, credit the construction villages and towns. From the start in 2002, government started to release independent start-up loans for re-employment of laid-off unemployed workers in state-owned enterprises learning from the experiences of rural credit cooperatives.

The forth period (2005 nowdays), Beginning in December 2005, suppliers of rural micro-credit were diversified, and tried the way of commercial and market-oriented to develop. Initially, it is a micro-credit organization of commercialization of sustainable development, its basic characteristic is only loans, and not deposits, operating independently and assumption of the risk is its commercial principle. RiShenglong, in jinzhongpingyao, is the first small loan company in China. By the end of 2006, CBRC relaxed the policy of market access to rural financial 
institutions, and allowed private capital to pilot in loan companies, village banks, and rural cooperatives. March 2007, China issued guidance on the development of rural micro-credit carried out in banking and financial institutions and made specific provisions on small loan business. June 2007, China postal savings bank micro-credit business was started in Henan province. After careful selection, Xingxiang and other three cities were chose as the place to make experiments, and chose ten middle developed County such as Changheng in Xingxiang. May 2008, CBRC and central bank published the guidance on the pilot of rural micro-credit united, small loan companies as corporate, its legitimacy was confirmed. Zhejiang province decided to start small loan company pilot.

At this stage of our country, Microfinance institutions including the following several categories:

The first category is the micro-credit of rural Credit Cooperatives. So far, the micro-credit of rural Credit Cooperatives has many features, such as wide coverage, large volume of business, and large volume of business.

The second category is the micro-credit of postal savings bank. Recently, postal savings bank is the financial institution which covers the largest the rural market, the scale of bank self-dots and post agent network is up to 37000 , the coverage of the network is wide, sources of funding is sufficient, and its cost is low relatively. Just because of bank self-dots' distribution characteristics, this kind of micro-credit may become one of the dominant forms of micro-credit.

The third category is the wholesale microfinance of China Development Bank and Agricultural Development Bank and other Policy banks. Policy-oriented financial institutions loan the fond to Rural Credit Cooperatives, Postal savings bank and other Microfinance institutions, which has the nature of poverty alleviation.

The forth category is the micro-credit of non-profit non-governmental organizations, such as the Microfinance institutions that established by China Foundation for Poverty in 2000. Its source of funds is single which mainly depends on the donations of non-profit non-governmental organizations.

The fifth category is microfinance institutions that created by private and absorbed public deposits to some degree.

The sixth category is commercial micro-credit companies. They generally register at the Trade and Industry Department, not absorb public deposits, and undertake business loan, their business object is small and medium-sized rural enterprises not general farmers, Pilot micro-credit companies of Central bank belongs to this kind.

The seventh category is the micro-credit of village bank and rural non-governmental capital mutual aid organizations. The number of this mode is small, and exists in pilot framework of CBRC nowadays.

China's rural micro-credit has been achieving great achievements. December 26, 2007 to 27, "China's rural micro-credit in international forums" was held ceremoniously in Haikou, the theme is "Micro-credit, Serve for Sannong". At Forum, all kinds of microfinance institutions introduced much successful experience, however, we generally felt that China's rural micro-credit is in the "low period". Among in 240 million farmers, there are 120 million farmers need loan, well, $67,000,000$ are general credit cooperatives. Recently, there're about 300 micro-credit organizations, but lots of them are unsustainable. That is, China's rural micro-credit is in the experimental stage and the unique technology doesn't come into being, we have to analysis in depth.

\section{The challenge that China's rural micro-credit's development faced}

\subsection{Channels of sources of funding are narrow}

State-owned commercial bank loans permissions has been taken, Substantial deposits absorbed by Grass-roots business organizations can only be deposited to superior bank, this causes lots of the county's fond runs into cities, the injection of agricultural credit isn't sufficiently. Pilot micro-credit companies face lacking money, whereas, village bank is bad at absorbing deposits in short time; Second, Postal savings have a foot in the local deposits, and Rural Credit Cooperatives have another, lacking money is a big challenge. From the overall situation, various credit subjects' fond aren't enough, supporting "Sannong" is not within our power.

\subsection{Micro-credit's high risk and high cost influence its sustainable development}

Compared with other industries, agriculture has the features of instability, property of weakness, and externalities. Farmers are the users of micro-credit, which lack effective assets, in this way ability to regain loans greatly relies on production and operation situation of farmers and the degree of personal credit. Second, because micro-credit are mainly used in plant industry, aquaculture and other small-scale production and operations which are closely related to natural conditions, the unpredictability of natural disasters add the risk of micro-credit's callback. The cost of micro-credit is certainly high owing to conducting loaning to single family.

\subsection{Rural micro-credit granting management is imperfect that affects the sustainability of loan}

At the procedure of releasing farmers small loans, because of lacking unified operational management methods and working procedures, not strict system, and confusing the different concept and content of farmers ratings, credit and lending, this causes unconditional credit and lending when farmers gained credit rating, the view that rating decides every thing, and confusion of basic conditions (credit) and lending conditions. At the process of operation, it based on 
subjective judgments, there are too many variables and difficult to control, as well, the use of the loans is too flooding. On the level of rural productivity, its risk is difficult to control and expected recovery rate is more difficult to achieve if we release excessive rural consumer loans.

\subsection{The service related to credit is lagging seriously}

Because publicity is not in place, some farmers view loan as the fond of poverty alleviation, risk their own strengths and needs to follow the trend of loaning. Some places' investment failed and its loans couldn't be return at the process of industrialization of agriculture's structural adjustment, as the result of not understanding technology and blinding investment.

\section{Some advice to the sustainability of micro-credit}

\subsection{Adopt Community Investment Act to solving the lack of fond}

It's not enough that the fond of micro-credit is only supplied by the local saving, between 1980s and 1990s, our countryside have made great contribution to the city building, the urban-rural gap is gradually expanding, now we can conduct industry-financed agriculture and city-financed rural. Outboard experience does have community investment act, it formulates that Commercial Banks have to invest a certain proportion of funds to the countryside. Thailand, for example, formulates that no matter which Commercial Bank, $20 \%$ of the fond must be invested to the rural, and it can be invested by itself or commissioned to others to invest, Central One document in 2005 has proposed this idea, but at that time, this idea referred to county's fund community investment, according to the idea of Thailand and USA, it covered all over the country already. If we have such a compulsory mechanism, maybe the problem of rural finance can have a greater ease.

\subsection{Perfect risk transfer and guarantee mechanisms, enhance the comprehensive agricultural support capacity and the overall disaster response capacity}

I suggest that when we are establishing and improving the government-led security system in agriculture, we can establish micro-credit guarantee funds for special projects which are used to subsidy the main body of rural micro-credit's a certain proportion of the loss, and institutionalize and standardize micro-credit project eligibility and the method of subsidization.

\subsection{Make farmers micro credit interest rates market-oriented}

Micro credit is different from banks generally loan processing. The former has the feature of small quantity and high cost, the key to profitability for microfinance institutions is loan pricing and cost management, that is, interest rate pricing need to cover the cost of credit. However, China's relevant laws stipulate that more than four times the benchmark interest rate belong to Usury and this is a contradiction. If micro-credit wants to achieve the goal of sustainable commercial, its lending rate must be much higher than that of general commercial banks. Giving full consideration to the cost of funding sources, loan management costs, farmer affordability and the situation of funding needs in rural areas, we should calculate breakeven point with adding normal profit to come up with the reasonable level of interest rates of micro credit. Nowadays, interest rates can be higher relatively, in this way the farmers can undertake to make up the higher loan cast. But it is not good if the interest rates is much too high, one way to reduce interest rates is to give preferential treatment at aspects such as tax and so on, the nation can subsidy some. But the more important one is competition, at a place should not result in monopolization, there should be 2 or 3 agencies doing it together, and the interest rates will decline naturally, this is international experience, that is to take step by step approach to do market-oriented reforms towards micro-lending rate.

\subsection{Improve the credit rating system and set up a farmer credit record}

Giving credit rating system provisions on law to avoid randomness of farmer credit limit, and establishing scientific criteria for rural micro-credit system, with applicability of progressive lending, are propitious to set up good rural credit system. We can refer to "Tax-credit rating management methodologies" issued by State Administration of Taxation in July 2003 and "Agricultural Development Bank of China enterprise credit rating loans provisional Ways" issued in May 2002, and classify farmers credit into four agricultural level ABCD, refine the specific criteria of all level, and carry out the job of farmers credit rating regularly. We should conduct rural research in depth, set up a sound farmer economic file, and prevent the risk of users to assess the false record. We need to set up barriers at the respect of conditions, quality, and rates and so on for discreditable farmers, and strengthen credit awareness of farmers. At the same time, Local Government should take part in it positively, strengthen the rural credit system construction, and promote the formation of rural credit system through strengthening supervision of the use and recycling of the farmer loans and controlling and eradicating situation of escaping debt.

\subsection{Issue policies that are good to promote the development of micro credit, especially the development of poverty} alleviation micro credit

Micro credit's large-scale development needs our nation's help. We should advocate pilot at different places and 
institutions, encourage moderate competition, and award for the excellent, fine the bad. Firstly, we should issue policies to encourage the development of micro credit from the micro-level, such as provisional management method, it gives people legal identity; we should give channels and financial support for the poverty alleviation micro credit institutions from the concept level, and establish wholesale funding agencies and organizations which only serve for them, such as policy banks, they conduct the job of issuance, management and supervision. Secondly, we have to offer the support of the quality of personnel management and training opportunities, and conduct the training of micro-credit project to make them learn the new technology, especially learn how to adjust themselves' breeding, cultivation and production methods to meet the demand of the market. It is important to improve the abilities of adjusting market, applying new technologies and loans, as well, improving the success rate of investment projects and reducing the risk of micro-credit are vital. At last, we should encourage microfinance institutions to establish industry self-regulatory mechanism, now industry self-regulatory organizations are incompact, we call one of them Micro-credit to promote the network, in fact, it is the predecessor of loose organizations, and we can encourage this kind of organizations to be self-disciplined.

In all, the solution of rural issues is a complex systems engineering, farmers, especially medium low-income farmers, are the vulnerable groups of society, country should not only offer assistance in policy, but also give the capital and administrative support, moreover, we need to put in true feelings. And then, we have to continuous improved China's rural micro-credit market and micro-credit operation efficiency and quality to promote the sustainable development of micro-credit.

\section{References}

Bu, Yanhong. (2008). Post Bank Micro credit Development of the characteristics and advantages. Commercial Banks, (2): 63-64.

China's rural micro-credit in international forums, record of the third unit. Sina Finance. [Online] Available: http://www.sina.com.cn (Retrieved from December 26, 2007)

Guo, Peiqing. (2007). The research of "Yunus microcredit model". Western financial, (8): 23-26.

Zhang, Jie. (2007). Rural micro-credit risk prevention and management. Price monthly, 11: 86-87. 